\title{
Learning is impaired by activated intentions
}

\author{
GABRIEL I. COOK \\ Claremont McKenna College, Claremont, California \\ AND \\ Richard L. Marsh, Arlo Clark-Foos, And J. Thadeus Meeks \\ University of Georgia, Athens, Georgia
}

\begin{abstract}
Two experiments examined the task interference that sometimes accrues from having an intention. In standard prospective memory tasks, latency is often slower to an ongoing task performed concurrently with having an intention than it is when no intention is given. If the locus of this slowing resulted from different attentional allocation policies in the two cases, we predicted that the process of learning a word list would be impaired if participants had an intention rather than if they did not. Four different event-based prospective memory tasks were used in Experiment 1 to demonstrate that worse free recall of a word list resulted when studied with a concurrent intention than with a control condition that had no intention. In that experiment, linking an intention to a distal context that was to occur after learning did not impair free recall. Two time-based tasks were used in Experiment 2 to demonstrate that possessing a time-based prospective memory also hinders learning, unless the intention is linked to a future context that is expected to occur after the study session. In the latter case, no impairment was obtained.
\end{abstract}

Human memory subserves a multitude of critical functions. One of these is the ability to plan an activity at one time, then at some later time to recover the intention in order to fulfill it. Of the variety of human intentions that have been studied, none has received more attention than event-based prospective memory (e.g., Henry, MacLeod, Phillips, \& Crawford, 2004; Kliegel, Martin, McDaniel, \& Einstein, 2004; McDaniel, Guynn, Einstein, \& Breneiser, 2004; West \& Krompinger, 2005). In these tasks, a person forms an intention to accomplish some activity (e.g., purchase a gift from an Internet vendor) but lets an environmental cue (e.g., that person's home computer) serve as an effective reminder. There is no recording of the intention on a to-do list; rather, the person is relying on the environmental cue to trigger recollection of the intention at a time when it is convenient to fulfill the task. The fragility of this type of memory is amply demonstrated by the numerous variables that have been shown to affect it-namely, how engrossed one is in other activities (e.g., Marsh, Hancock, \& Hicks, 2002; Marsh \& Hicks, 1998), how distinctive or familiar the cue is from the background (McDaniel \& Einstein, 1993), whether the current context matches the encoding context (McDaniel, Robinson-Riegler, \& Einstein, 1998), and whether one is impaired by aging (e.g., Maylor, 1998) or by being a member of a neuropsychologically impaired population (Maylor, Smith, Della Sala, \& Logie, 2002). From this perspective it is amazing that people successfully rely on this strategy in their everyday life, but they do (Marsh, Hicks, \& Landau, 1998).
One issue that has arisen recently in the prospectivememory literature is the degree to which having an intention usurps resources from other ongoing activities. In some cases, resources may be needed to detect an eventbased cue, thereby leaving fewer resources for the cognitive $\operatorname{task}(\mathrm{s})$ at hand (labeled the ongoing task $[s]$ in this literature). In other cases, no resources may be needed for cue detection, in which case the ongoing task can be performed as well as it can when no intention has been formed. According to the preparatory attention and memory view, all cases of event-based prospective memory fall into the former variety and always usurp resources from ongoing activities (Smith, 2003; Smith \& Bayen, 2004). By contrast, the multiprocess view classifies intentions into a continuum, progressing from those that completely usurp resources from the ongoing task to those that can be retrieved spontaneously and do not affect ongoing task performance (e.g., Einstein et al., 2005). The conditions that tend to foster spontaneous retrieval (and thereby produce less interference or none at all) include (1) having a single, specific cue related to the intention, (2) ensuring that the cue is in focal attention, (3) processing in the ongoing task that fosters cue identification, (4) increasing the relatedness of the cue and the target action to be performed, and (5) having salient cues that stand out from their background (see McDaniel \& Einstein, 2000).

The gold standard in many studies that examined these issues was whether task interference occurred-that is, whether or not RTs to performing the ongoing activity

G. I. Cook, gabriel.cook@cmc.edu 
were slower when participants performed the activity with, rather than without, an intention. Being asked to respond to one or two specific cues tends not to evoke any task interference (e.g., Einstein et al., 2005; Hicks, Marsh, \& Cook, 2005). By contrast, being asked to respond to items from a category (e.g., "Respond to words denoting furniture") does cause task interference, as does having a timebased intention, or asking people to respond to six specific, event-based cues (Smith, 2003). Time-based intentions ask participants to monitor the passage of time and to respond at a specific time or during a window of time.

Given the foregoing, the present study addressed the simple question of whether the field of prospective memory is limited to studying task interference using the dependent variable of RTs. Theoretically, if having an intention truly usurps resources from an ongoing task, it should be possible to observe this deleterious effect in another dependent variable, such as memory for the material in the ongoing task. In Experiment 1, we tested people's memory using a free-recall task for the information processed while an event-based intention was activated. Prior uses of RTs in, say, a lexical decision task or color matching task are actually measuring task interference at discrete points in time. By contrast, in Experiment 1, the cost of holding an intention on learning is likely to be exerted across the entire study phase, not just at discrete points in time. Consequently, the cost of having a particular intention may be more sensitively measured by the decrement to recall rather than a latency at a discrete point in time. In Experiment 2, we extended this comparison to a timebased intention and manipulated with a contextual association, whether or not the intention was activated during the learning phase.

\section{EXPERIMENT 1}

In Experiment 1, participants studied 40 words. The nointention control group did not have an intention, whereas three other conditions were given a categorical intention, a one-word specific cue to which they were to respond, or a six-word set of specific cues. If task interference, as evidenced in this literature as RT slowing, is truly usurping resources from the ongoing activity (in this case studying words for a later memory test), free recall should be lower in the conditions where the intention is activated than in the control group without an intention. One natural alternative prediction is that participants check each word to determine whether it matches the intention (Guynn, 2003), and this extra checking might actually increase free-recall performance.

Recently, Marsh, Hicks, and Cook (2006) demonstrated that if an intention is linked to a distal context that is clearly demarcated by different activities, no task interference occurs over intervening activities until the context is reached where the intention is relevant. We capitalized on that finding by running a second control condition in which the categorical intention was linked to a distal context that was slated to occur after learning of the list was completed. If no task interference occurred because the intention was linked to a distal context, free recall perfor- mance should be at comparable levels to the no-intention control condition.

\section{Method}

Participants. Undergraduate students from the University of Georgia volunteered in exchange for partial credit toward a research appreciation requirement. Each participant was tested individually in sessions that lasted approximately $20 \mathrm{~min}$. Thirty participants were assigned to each of four conditions, but through a miscommunication 34 were tested in the context-linked control condition; accordingly, 154 participants were tested in all. The data for an additional five participants ( $3 \%$ of the sample) were discarded prior to scoring because they recalled 0,1 , or 2 words out of 40 (i.e., less than $5 \%$ ). Excluding these participants actually works against our main hypothesis; nevertheless, we considered them to be inattentive outliers at the low end of the free-recall scale.

Materials and Procedure. Forty high frequency words were chosen from the Kučera and Francis (1967) corpus that should support respectable levels of free recall in the control conditions $(M=$ $130.63, S D=5.39$ ). During study, these words appeared one at a time in the center of the computer monitor for $5 \mathrm{sec}$ each and the software randomized the presentation sequence anew for each participant tested. Prior to studying the word list, for the study phase participants received written instructions that were verbally reiterated by the experimenter. In the no-intention control condition, these were the only instructions. In the four intention conditions, prospective memory instructions were delivered. In the categorical condition, participants were asked to press the "/" key if a word denoting furniture ever appeared (the example desk was provided). In the context-linked control condition, participants were told that they would be studying a second list of words (which was not true) and that the intention to respond to furniture was not relevant until they studied that second list. In the one-specific cue condition, they were asked to respond in an identical manner if the word desk was on the study list. Finally, in the six-specific cues condition, participants were asked to respond if they saw one of the following six words: four, score, seven, years, ago, today. Obviously, these represent the first six content words of President Lincoln's Gettysburg Address. We used them so that the time spent learning the intention would be roughly comparable to that spent in the other event-based conditions. Had we used criterion learning for six other unrelated words, this would have taken several minutes and confounded the timing among the conditions. After the instructions, all participants were given an arithmetic (multiplication) distractor task for $3 \mathrm{~min}$, as timed by the computer software controlling the experiment. At the conclusion of the distractor task, the experimenter commenced the study phase without reference to the prospective memory task. One important feature of the study phase was that no prospective memory cue ever appeared during learning, so there was no opportunity for differential reminding across the tested conditions.

After studying the list of items, another distractor period ensued for $4 \mathrm{~min}$ prior to the free recall period, in which participants attempted to finish the page of arithmetic problems they had begun earlier. Participants were then given 4 min to write down as many words as they could remember from the study phase. These recall protocols were scored against a master list, without regard to spelling. Intrusions were recorded as well, but because they are very rare in free recall (Bower \& Mann, 1992), we did not report them.

\section{Results and Discussion}

Unless otherwise specified with a $p$ value, no statistical test exceeds the conventional $5 \%$ probability of a Type I error. The data are represented in Figure 1 with error bars representing the standard error of the mean. As can be seen in Figure 1, both the no-intention control condition and the context-linked control condition exhibited better free recall than did the three conditions in which participants held 


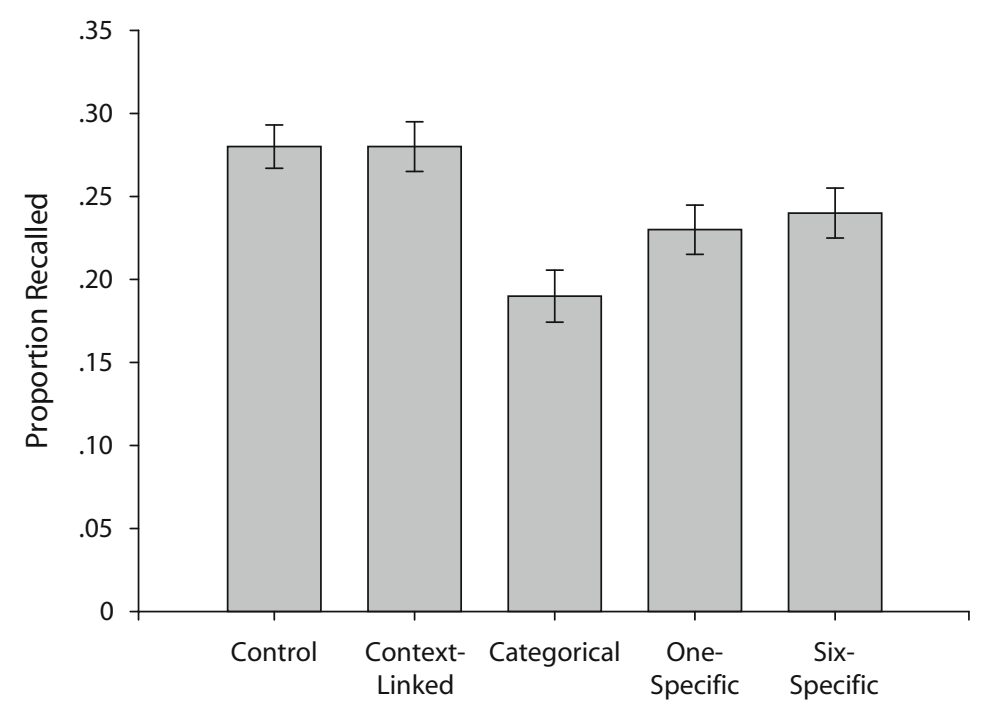

Figure 1. Average proportion recalled for the no-intention and context-linked control conditions and the three conditions holding an event-based intention in Experiment 1. Bars represent standard errors of the mean.

event-based intentions. In the one-way ANOVA model, the omnibus test supported this conclusion $[F(4,144)=6.36]$. A planned contrast of the two control conditions against the three conditions with intentions also supported this conclusion $[t(144)=4.37]$. The follow-up pairwise tests also declared better performance in the no-intention control condition than in the categorical $[t(58)=4.38]$, the one-specific $[t(58)=2.35]$, and the six-specific $[t(58)=$ $2.05]$ conditions. The same was also true using the contextlinked control condition as compared with the categorical $[t(58)=4.11]$, the one-specific $[t(58)=2.16]$, and the six-specific $[t(58)=1.87, p=.06]$ conditions.

The three intention conditions also differed from one another by omnibus ANOVA $[F(2,89)=3.11]$. Free recall appears to be lowest with a categorical intention rather than the two conditions that used specific event-based cues. This appearance was confirmed with follow-up tests between the categorical condition and the one-specific cue condition $[t(58)=2.00]$, as well as the six-specific cues condition $[t(58)=2.26]$. This outcome is consistent with cue detection being better with specific cues than with a categorical intention (Einstein, McDaniel, Richardson, Guynn, \& Cunfer, 1995), as well as task interference being smaller or nonexistent with specific cues than with significant task interference with a categorical intention (Hicks et al., 2005). Therefore, the present results dovetail nicely with the existing literature suggesting that a categorical intention interferes more with an ongoing task than does an intention concerning specific cues.

We did not find better free recall in the conditions where participants held an intention. That outcome may constrain theories of prospective memory that posit that each item is inspected more carefully and checked against the intention itself (e.g., Guynn, 2003). Such a process might result in better memory for items. However, if the intention acted to disrupt strategic learning processes and consequently reduced subsequent free recall performance, then an item-by-item checking process might disrupt such strategic learning.

Nevertheless, two findings from this experiment deserve special note. First, a single specific cue disrupted subsequent free recall, whereas in the previous literature using a variable task interference dependent on RT is not usually found with one or two specific cues (e.g., Einstein et al., 2005; Marsh, Hicks, Cook, Hansen, \& Pallos, 2003). As we mentioned in the introduction, an intention may provide a constant load on learning processes whose effect is measurable as the cumulative effect on free recall. With a latency measure, only discrete measurements are taken which allow for the intention to be refreshed during downtime between trials (for further discussion, see Hicks et al., 2005, particularly Experiment 4). From this perspective, the disruption of learning may actually be a more sensitive dependent variable than is discrete-trial RT. If so, the data suggest that some caution is needed in claiming that RT is a more sensitive variable than is memory (e.g., Smith, 2003). Einstein et al. (2005) also found a difference in interference between one specific cue and six specific cues, whereas in this experiment we did not. This difference obviously stems from our use of the Gettysburg Address manipulation to equate learning time, whereas Einstein et al.'s participants had to engage in laborious, criterion learning of the six cues, thereby heightening the importance of the prospective memory task.

\section{EXPERIMENT 2}

The foregoing experiment clearly demonstrates a novel form of task interference - that is, disruption to learning processes from holding an intention. In the next experiment, we attempted to ascertain whether a time-based intention would have the same effect. Hicks et al. (2005) 
demonstrated that the RT slowing to a time-based and a categorical event-based task was comparable, thereby demonstrating similar task-interference effects. Therefore, the straightforward prediction is that a time-based intention should also hamper learning, as tested by a later free-recall task. We tested three conditions in this experiment: a no-intention control condition, a standard timebased task in which participants were asked to press a key after 4 min had elapsed, and a context-linked time-based condition in which participants also had to respond after 4 min but were explicitly told that the 4 min mark would occur after the study phase. If the detrimental effect on recall from holding an event-based intention is a general finding, time-based intentions should produce a similar deficit in recall. To the extent that contextual associations can alleviate the interference of an intention, recall should only suffer for words studied in a context in which the intention is competing for valuable cognitive resources, but not before reaching that context.

\section{Method}

Participants. Undergraduates from the University of Georgia volunteered in exchange for partial credit toward a research appreciation requirement. Each participant was tested individually in sessions that lasted approximately $20 \mathrm{~min}$. Participants were quasirandomly assigned to the three experimental conditions. Thirty participants were assigned to each condition, for a total sample size of 90. As in Experiment 1, prior to scoring four participants' (about $4 \%$ ) data were discarded because the participants failed to recall more than 2 of the 40 studied words.

Materials and Procedure. The basic experiment was identical in all respects to Experiment 1, except that participants given an intention were asked to press the "/" key after 4 min had elapsed. They were also told that they could check the computer clock at any time by pressing the "Z" key. Doing so brought up a small clock in the upper right-hand corner of the computer monitor for $1 \mathrm{sec}$. For example, 2:36 indicated that $2 \mathrm{~min} 36 \mathrm{sec}$ had elapsed. Because participants did not know that the duration of the study phase was just over $3 \mathrm{~min}$, the intention should be activated for the standard timebased intention condition. In the context-linked control condition, the 4-min intention was also given. However, these participants were informed that the 4-min marker would occur in the next task, after they had finished studying the words. Therefore, if the Marsh, Hicks, and Cook (2006) finding of no task interference over an intervening context holds here, the intention will not be activated during learning in this condition, and there should be no free recall deficit.

\section{Results and Discussion}

The data are summarized in Figure 2 using the same conventions as before. Descriptively, the time-based intention disrupted performance relative to the no-intention control condition when it was active during the learning phase; but, when the time-based intention was linked to a future context temporally beyond the learning phase, it produced no interference at all. Thus, Marsh, Hicks, and Cook's (2006) contextual association finding was replicated here, as in Experiment 1, using a nonlatency measure. The omnibus ANOVA confirmed these impressions $[F(2,89)=4.15]$. Whereas the standard time-based condition exhibited worse free recall than the no-intention control group $[t(58)=2.38]$ and the context-linked time-based condition $[t(58)=2.15]$, the control and the context-linked conditions did not differ from one another $[t(58)<1]$. Thus, a time-based intention disrupted learning unless participants linked that intention to a future context. Participants in the standard time-based condition checked the clock an average of 3.10 times, whereas participants in the context-linked condition checked only 1.97 times. This numeric difference was not statistically significant $[t(58)=1.65]$, but would be just on the margin, had we used a one-tailed test $(p=.05)$.

\section{GENERAL DISCUSSION}

The experiments reported to date that have studied task interference have done so with a latency metric of performance. Participants who held an active intention responded more slowly to the ongoing task than when

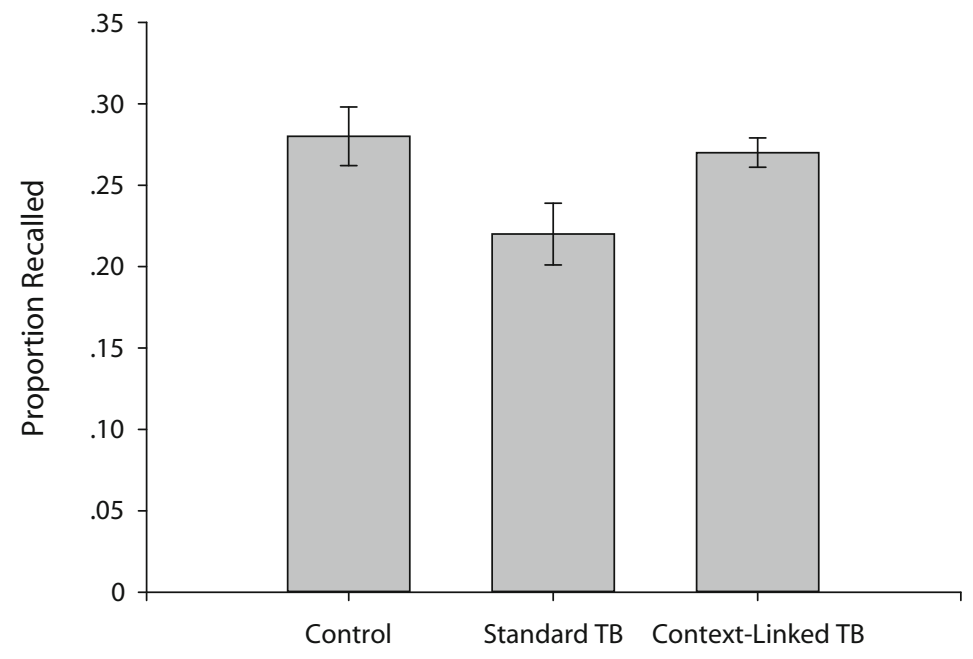

Figure 2. Average proportion recalled for the no-intention control condition and the two conditions holding a time-based intention in Experiment 2. Bars represent standard errors of the mean. 
no intention was given. In general, this slowing has been interpreted as a sort of dual task trade-off, with most resources being devoted to the ongoing task but some fraction thereof being allocated to the prospective memory task. Our own work in this area has depicted the trade-off as an attentional allocation policy that is established at the outset of the ongoing task (e.g., Hicks et al., 2005; Marsh, Cook, \& Hicks, 2006; Marsh, Hicks, \& Cook, 2005). The amount of attention that is devoted to the entire task set (i.e., both the ongoing and the prospective memory tasks) is determined by motivational and metacognitive factors such as how difficult or easy the participant believes it will be to succeed at both tasks. The attention allocated to the prospective task will increase and diminish, depending on the local characteristics of the current task's demands. For example, we have demonstrated that if participants can predict that the material on an upcoming trial is not relevant to their intention, they will respond more quickly to the ongoing task, presumably because attention that otherwise would have been used to detect an event-based cue can be used profitably to perform the ongoing task (Marsh, Cook, \& Hicks, 2006).

The two experiments reported here demonstrate that either a time-based or an event-based intention, if active, will interfere with the cognitive processes that foster learning. Thus, we found an interference effect similar to that found with latency metrics. The current findings, however, may have more practical ramifications than did previous demonstrations of this sort of effect. Although it is true that in past demonstrations participants holding an intention produced slower RTs on the ongoing task, they nevertheless were generally as accurate on that task as control participants who did not hold an intention. Of 20 or so experiments reporting ongoing task accuracy, in only two has it been found that having an intention reduces accuracy (see Einstein et al., 2005; Smith \& Bayen, 2006). In the current case, we found that one consequence of holding an intention was to reduce free recall anywhere from $11 \%$ to $32 \%$, depending on the intention. This substantial reduction is far more dramatic than the two existing cases, and must arise from interfering with the creation of interitem associations that are generally believed to support free recall performance. Although our experiments do not isolate the locus of the effect more precisely, they do demonstrate that there are tangible costs to holding an intention. If one extrapolates these findings to everyday life, a request from one's secretary to retrieve class materials could interfere with retaining some of the paragraph that one wants to finish reading first. As demonstrated in both experiments, if the intention is linked to a distal context, such as retrieving the materials after lunch, then the current results suggest that no interference (or episodic memory deficit) will occur at all.

One criticism of the current results is that we have been comparing a latency measure of cost to a free recall measure of cost without ever testing both types of costs in the same experiment. In response to this criticism, we conducted a naming latency experiment, in which the 40 items used in these experiments were named during encoding (for procedure details consult Marsh, Hicks,
\& Watson, 2002, Experiment 3). Two groups of 30 participants were tested. One held an intention to respond to furniture and the other was given no intention. Subsequent to the distractor task procedures described earlier, all participants were given a free recall task. Not surprisingly, naming latency was longer for the group that had the intention $(776 \mathrm{msec})$ than for the no-intention control group $(706 \mathrm{msec})[t(58)=2.68]$. But free recall was also lower in the intention condition (.15) than in the control condition (.18) $[t(58)=1.91, p=.06]$. The lower level of free recall and the attenuation of the free recall differences are a consequence of the much shorter encoding time per word in this experiment. However, our point is that, although the two dependent measures appear to be measuring the same construct (cost to performance), which of the two measures is to be preferred depends on the particulars of the ongoing task and the goals of the experiment.

Another conceptual issue not addressed by our experiments is the fact that we never presented an event-based cue during the learning phase. On the one hand, perhaps participants were anticipating the cue and wondering when one would occur, in which case there may be a greater load during learning than if a cue had actually occurred. On the other hand, actually receiving the cue and detecting it might remind participants of their concurrent intention, in which case the load might have been greater if a cue had occurred. Of course, Marsh et al. (2005) argued that attentional allocation policies were set at the outset of a task set and adjusted later according to task demands and the changing conditions of the ongoing task, if any. From that perspective, presenting or not presenting a cue may not affect performance at all over the brief period of presenting 40 words; which of these outcomes is more likely is unclear.

Previously we argued that prospective memory requires an optimum level of more centrally mediated resources, and furthermore, that prospective memory as a subdiscipline lies squarely at the crossroads of attention and memory (Marsh \& Hicks, 1998). Einstein et al. (2005) have claimed that a single, specific cue can deliver an event-based intention to consciousness by spontaneous retrieval that requires no attentional resources being diverted from the ongoing task. Part of their evidence was an absence of slowing to the ongoing task using a single cue. Of course, the absence of evidence is not evidence of absence, as the results from Experiment 1 demonstrate. We do find a sizable reduction in free recall with a single, specific cue. Empirically, that finding suggests that our learning paradigm is capturing an attentional allocation policy change, from having no intention at all, that does not reveal itself readily in an RT performance metric. Just as Ebbinghaus (1913) showed that savings in relearning is a very sensitive dependent variable of what is stored in memory, perhaps what we have shown here is that task interference can be profitably studied by using a learning paradigm that can sometimes be more sensitive to divisions of attention than is an RT metric of interference.

\section{AUTHOR NOTE}

We thank Field VanMeter, Stacia Fink, Jessica Scalise, and Lily Inglima for their dedicated help in collecting the data. We also thank 
Gil Einstein, Rebekah Smith, and Rob West for helpful comments on an earlier draft of the article. Correspondence concerning this article should be addressed to G. I. Cook, Department of Psychology, Claremont McKenna College, 850 Columbia Avenue, Claremont, CA 91711 (e-mail: gabriel.cook@cmc.edu).

\section{REFERENCES}

Bower, G. H., \& ManN, T. (1992). Improving recall by recoding interfering material at the time of retrieval. Journal of Experimental Psychology: Learning, Memory, \& Cognition, 18, 1310-1320.

Ebirnghaus, H. (1913). Memory: A contribution to experimental psychology. New York: Teachers College Press. Reprinted Bristol: Thoemmes Press, 1999.

Einstein, G. O., McDaniel, M. A., Richardson, S. L., Guynn, M. J., \& CUNFER, A. R. (1995). Aging and prospective memory: Examining the influences of self-initiated retrieval processes. Journal of Experimental Psychology: Learning, Memory, \& Cognition, 21, 996-1007.

Einstein, G. O., McDaniel, M. A., Thomas, R., Mayfield, S., Shank, H., Morrisette, N., \& Breneiser, J. (2005). Multiple processes in prospective memory retrieval: Factors determining monitoring versus spontaneous retrieval. Journal of Experimental Psychology: General, 134, 327-342.

GuYNN, M. J. (2003). A two-process model of strategic monitoring in event-based prospective memory: Activation/retrieval mode and checking. International Journal of Psychology, 38, 245-256.

Henry, J. D., Macleod, M. S., Phillips, L. H., \& Crawford, J. R. (2004). A meta-analytic review of prospective memory and aging. Psychology \& Aging, 19, 27-39.

Hicks, J. L., Marsh, R. L., \& CoOK, G. I. (2005). Task interference in time-based, event-based, and dual intention prospective memory conditions. Journal of Memory \& Language, 53, 430-444.

Kliegel, M., Martin, M., McDaniel, M. A., \& Einstein, G. O. (2004). Importance effects on performance in event-based prospective memory tasks. Memory, 12, 553-561.

KuČEra, H., \& FranCIS, W. N. (1967). Computational analysis of present-day American English. Providence, RI: Brown University Press.

MARSh, R. L., CoOK, G. I., \& Hicks, J. L. (2006). Task interference from event-based intentions can be material specific. Memory \& Cognition, 34, 1636-1643.

Marsh, R. L., Hancock, T. W., \& Hicks, J. L. (2002). The demands of an ongoing activity influence the success of event-based prospective memory. Psychonomic Bulletin \& Review, 9, 604-610.

Marsh, R. L., \& HicKs, J. L. (1998). Event-based prospective memory and executive control of working memory. Journal of Experimental Psychology: Learning, Memory, \& Cognition, 24, 336-349.

Marsh, R. L., Hicks, J. L., \& CoOK, G. I. (2005). On the relationship between effort toward an ongoing task and cue detection in event-based prospective memory. Journal of Experimental Psychology: Learning, Memory, \& Cognition, 31, 68-75.

Marsh, R. L., Hicks, J. L., \& CoOK, G. I. (2006). Task interference from prospective memories covaries with contextual associations of fulfilling them. Memory \& Cognition, 34, 1037-1045.

Marsh, R. L., Hicks, J. L., Cook, G. I., Hansen, J. S., \& Pallos, A. L. (2003). Interference to ongoing activities covaries with the characteristics of an event-based intention. Journal of Experimental Psychology: Learning, Memory, \& Cognition, 29, 861-870.

MarSh, R. L., Hicks, J. L., \& LANDAU, J. D. (1998). An investigation of everyday prospective memory. Memory \& Cognition, 26, 633-643.

Marsh, R. L., Hicks, J. L., \& Watson, V. (2002). The dynamics of intention retrieval and coordination of action in event-based prospective memory. Journal of Experimental Psychology: Learning, Memory, \& Cognition, 28, 652-659.

MaYlor, E. A. (1998). Changes in event-based prospective memory across adulthood. Aging, Neuropsychology, \& Cognition, 5, 107-128.

Maylor, E. A., Smith, G., Della Sala, S., \& Logie, R. H. (2002). Prospective and retrospective memory in normal aging and dementia: An experimental study. Memory \& Cognition, 30, 871-884.

McDaniel, M. A., \& Einstein, G. O. (1993). The importance of cue familiarity and cue distinctiveness in prospective memory. Memory, $1,23-41$

McDaniel, M. A., \& Einstein, G. O. (2000). Strategic and automatic processes in prospective memory retrieval: A multiprocess framework. Applied Cognitive Psychology, 14, S127-S144.

McDaniel, M. A., Guynn, M. J., Einstein, G. O., \& Breneiser, J. (2004). Cue-focused and reflexive-associative processes in prospective memory retrieval. Journal of Experimental Psychology: Learning, Memory, \& Cognition, 30, 605-614

McDaniel, M. A., Robinson-Riegler, B., \& Einstein, G. O. (1998) Prospective remembering: Perceptually driven or conceptually driven processes? Memory \& Cognition, 26, 121-134.

SмITH, R. E. (2003). The cost of remembering to remember in eventbased prospective memory: Investigating the capacity demands of delayed intention performance. Journal of Experimental Psychology: Learning, Memory, \& Cognition, 29, 347-361.

SMITH, R. E., \& BAYEN, U. (2004). A multinomial model of prospective memory. Journal of Experimental Psychology: Learning, Memory, \& Cognition, 30, 756-777.

SMITH, R. E., \& BAYEN, U. (2006). The source of adult age differences in event-based prospective memory: A multinomial modeling approach Journal of Experimental Psychology: Learning, Memory, \& Cognition, 32, 623-635.

West, R., \& Krompinger, J. (2005). Neural correlates of prospective and retrospective memory. Neuropsychologia, 43, 418-433.

(Manuscript received November 8, 2005; revision accepted for publication May 24, 2006.) 